\title{
Canada suicide prevention efforts lagging, experts say
}

$\mathrm{T}$ hirty years after turning the international spotlight on suicide, Canada still doesn't have a national strategy for suicide prevention.

More than one million people around the world die by suicide each year, according to the World Health Organization (WHO). Suicide is also one of the top 10 leading causes of death in Canada, accounting for some 4000 deaths annually.

Canadian experts were among the first to call attention to suicide as an international public health issue, but prevention efforts closer to home have since stalled in jurisdictional quagmires.

"We were world leaders when Canada hosted its first international conference on suicide prevention in 1979. Within a year, we had a federally-funded task force on the issue," says Richard Ramsay, president of LivingWorks, an international suicide intervention training company based in Calgary, Alberta. "But in the seven years it took for that task force to report back, other countries had already implemented national strategies."

Canada also contributed expertise and tax dollars in 1995 to draft the United Nations' guidelines for implementing national suicide prevention strategies. Crafted in Alberta, the UN initiative set out guidelines for establishing government policy, measurable objectives and best practices for implementation and evaluation.

Some countries, such as Australia, Scotland and the United States, subsequently used the document as a blueprint in developing national strategies and programs for suicide prevention.

Yet, Canada has failed to take the advice.

"The federal government never adopted the guidelines. They've never even gone on the record to say suicide is a national public health issue," says Marion Cooper, past president of the Canadian Association for Suicide Prevention. "That's damaging to people who've been bereaved by suicide, to

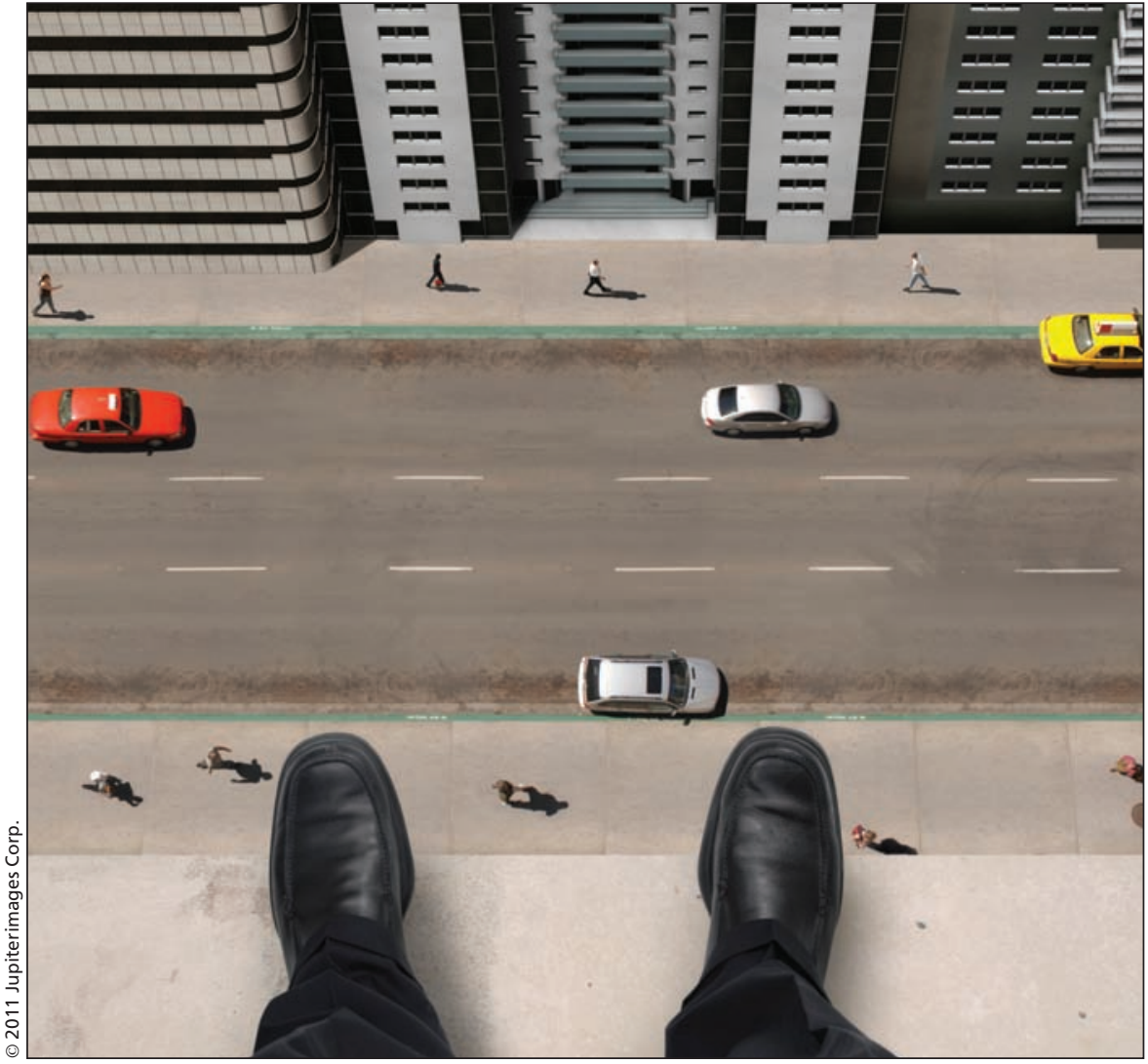

Reducing access to lethal means of committing suicide, improved reporting of suicide in the media, school-based programs, treatment of drug and alcohol problems and training for frontline workers in various professions are components of all current national suicide prevention strategies.

people who struggle with thoughts of suicide, because it adds to the shame and silence that already surround the issue."

Finland, Sweden, Norway, Australia and New Zealand were among the first to implement national suicide prevention strategies in the 1980s and 90s. They've since been joined by England, the US, Denmark, Germany and Scotland, among others.

National suicide prevention strategies differ in the target groups emphasized. For example, Australia's first national strategy and New Zealand's strategy primarily address the needs of young people, while Finland, Norway, Sweden and Australia's current national strategies have a broader focus on all age groups (www.health.gov.au /internet/main/publishing.nsf/content
/1D2B4E895BCD429ECA25722900 27094D/\$File/intprev.pdf).

In Canada, federal funding for suicide prevention has been targeted at Aboriginal youth in some 200 reserve communities across the country, says Cooper. "Of course we know that Aboriginal youth are disproportionately represented in our suicide statistics and it's important that funding be sustained, but when we look at suicide in Canada, there's also a significant burden among middle-aged women and older men, so a large proportion of people dying by suicide are not necessarily being reached."

Suicide prevention in Canada remains fragmented, disconnected and lacking a national vision, says Ramsay. "The UN guidelines listed all the things that could 
be part of a strategy and it was up to jurisdictions to decide want they wanted to do, but at least they started with the whole picture and worked down to their individual parts. In Canada, we're just starting from our disparate provincial or local parts without any idea of where they fit into the big picture."

At the root of fragmentation lie multilevel jurisdictional quarrels that take place over suicide prevention between the medical and nonmedical communities, as well as between the federal and provincial and territorial governments.

"In May, the federal minister of health told us that suicide is a mental health issue and, because there's already a national mental health commission, any other national efforts on suicide would be redundant and confusing for Canadians," Cooper says. "But if you look at the documents to come out of the commission so far, there's been only the briefest mention of suicide. They've been clear with us from the start that suicide prevention wasn't going to be embedded in their national mental health strategy."

There's also been a longstanding debate over whether suicide prevention should be handled exclusively by the medical community, again on the premise that suicide is rooted in mental illness, says Cooper. "Certainly there's evidence that many people who die by suicide experience mental health distress, but there are often other issues at play that couldn't be addressed by a strictly mental health-focused approach."

A multisector approach that includes health and nonhealth sectors, such as education, labour, justice, religion, law, politics and even the media, is recommended by the WHO as most effective in preventing suicide.

Reducing access to means of committing suicide, improved reporting of suicide in the media, school-based programs, treatment of drug and alcohol problems and training for frontline workers in various professions are components of all current national suicide prevention strategies (www.health.gov.au /internet/main/publishing.nsf/content /1D2B4E895BCD429ECA2572290027 094D/\$File/intprev.pdf).

The approach recommended by the WHO is beyond the purview of the provinces, even though, technically, suicide comes under their jurisdiction, says Cooper. "But all we hear from the federal minister is that health is a provincial matter. So the issue has gotten lost in a jurisdictional funding dance."

Some provinces - notably Quebec, New Brunswick, British Columbia, Manitoba, Nova Scotia and Alberta have implemented suicide prevention strategies. Others, such as Ontario and Saskatchewan, have not.

"There are always suicide prevention activities running locally, if not provincially or territorially, but there's no consistency in funding or focus," says Cooper.

Ramsay cites New Brunswick and BC as both having "excellent" strategies, "the difference is that New Brunswick had dollars and infrastructure to support it, whereas BC did not and just ended up with a fine document to circulate."

Ramsay says Canada has yet to build the critical mass of political or popular will necessary to see a national suicide prevention strategy pushed through Parliament. "Support came from both ends in the US, where a senator and a Republican each piloted policy positions on suicide through both the Senate and Congress, which gave the grassroots people a jumping-off point to call for a national strategy. We've never had that kind of enthusiasm in Canada, political or otherwise, although we've tried to find champions in the House."

Earlier in November 2010, a private member's bill to establish a panCanadian suicide prevention strategy was introduced in the House of Commons. New Democrat sponsor Megan Leslie would like to see the creation of a national strategy that would include the establishment of a national medical surveillance program for suicide prevention and risk identification. Such a strategy would also set standards for best practices and training in suicide prevention and require assessments of current access to mental health and substance abuse services, among others.

But many Canadians simply don't believe suicide prevention strategies work, says Cooper. "It comes down to this deep-seated, mistaken belief that if a person wants to commit suicide they're going to do it and there's nothing we can do to stop them."

Most countries have yet to complete evaluations of their strategies, but Finland, the first to adopt a national suicide prevention strategy in 1986 , reported a $9 \%$ decrease in suicide deaths over the first 10 years of implementation (www.stakes.fi/verk kojulkaisut/muut/mu161.pdf).

Other nations have seen smaller returns. Dr. Thomas Insel, director of the US National Institute of Mental Health says efforts to update a US strategy were launched in October (www.cmaj.ca/cgi/doi/10.1503/cmaj .109-3703), largely as a consequence of a "shocking" Department of Defence report that indicated "more soldiers were lost to suicide than to combat over the last five years" (http://usarmy .vo.llnwd.net/e1/HPRRSP/HP-RR-SP Report2010_v00.pdf).

However, it may be unrealistic to expect large reductions in national suicide rates as many strategies were only implemented in the last few years, Ramsay says. "Scotland conducted a cost-benefit study and found that with the millions of pounds they were investing in suicide prevention, if at the end of the day they saved five lives a year they'd be getting their money's worth. People look for these drastic reductions, but what they don't realize is that you don't need to cut suicide deaths by $10 \%$ to make it worthwhile." - Lauren Vogel, CMAJ

CMAJ 2011.DOI:10.1503/cmaj.109-3724 